\title{
Genomic Rearrangements in Trypanosomatids: an Alternative to the "One Gene" Evolutionary Hypotheses?
}

\author{
JC Dujardin/ ${ }^{+}$, J Henriksson*, K Victoir, S Brisse**, D Gamboa/***, \\ J Arevalo***, D Le Ray
}

\begin{abstract}
"Prins Leopold" Instituut voor Tropische Geneeskunde, Protozoology 155 Nationalestraat, B-2000 Antwerpen, Belgium *Department of Medical Genetics, Uppsala University, Biomedical Center, Box 589, S-751 23 Uppsala, Sweden **Eijkman-Winkler Institute, Utrecht University, Academic Hospital Utrecht, Heidelberglaan 100, 3584 CX Utrecht, The Netherlands ***Instituto de Medicina Tropical "Alexander von Humboldt", Departamento de Ciencias Fisiológicas, Universidad Peruana Cayetano Heredia, Lima, Peru
\end{abstract}

Most molecular trees of trypanosomatids are based on point mutations within DNA sequences. In contrast, there are very few evolutionary studies considering DNA (re) arrangement as genetic characters. Waiting for the completion of the various parasite genome projects, first information may already be obtained from chromosome size-polymorphism, using the appropriate algorithms for data processing. Three illustrative models are presented here. First, the case of Leishmania (Viannia) braziliensis/L. (V.) peruviana is described. Thanks to a fast evolution rate (due essentially to amplification/deletion of tandemly repeated genes), molecular karyotyping seems particularly appropriate for studying recent evolutionary divergence, including eco-geographical diversification. Secondly, karyotype evolution is considered at the level of whole genus Leishmania. Despite the fast chromosome evolution rate, there is qualitative congruence with MLEE- and RAPD-based evolutionary hypotheses. Significant differences may be observed between major lineages, likely corresponding to major and less frequent rearrangements (fusion/fission, translocation). Thirdly, comparison is made with Trypanosoma cruzi. Again congruence is observed with other hypotheses and major lineages are delineated by significant chromosome rearrangements. The level of karyotype polymorphism within that "species" is similar to the one observed in "genus" Leishmania. The relativity of the species concept among these two groups of parasites is discussed.

Key words: Leishmania - Trypanosoma cruzi - chromosome evolution

The DNA sequence and its variation - essentially by point mutations - underlie the discipline of molecular evolution. Methods of analysis and evolutionary models are robust and, according to the grade of conservation of the gene or intergenic region considered, studies at different evolutionary scales can be performed. Nevertheless, the adequacy between "one gene" trees, and "species" trees might be questioned. Indeed, only orthologous genes (homology resulting from spe-

Financial support from the Flemish Fund for Scientific Research (FWO, Grants 346/1990 and 9.0024.90), the Swedish Agency for Research Co-operation with Developing Countries (SAREC), the Economical Union (TS2CT90-0315, TS3-CT92-0155, TS3-CT92-0129, IC18CT96-0123 and IC18-CT98-0256) and FONDECYTChile (193/1043).

${ }^{+}$Corresponding author. Fax: 32.3 .2476362 or 2476359. E-mail: jcdujard@itg.be

Received 13 April 2000

Accepted 15 May 2000 ciation; Wiley 1981) should be used and several genes should be sequenced to confirm orthology and discard paralogous (homology resulting from gene duplication) and xenologous (result of gene transfer) genes (Larson 1994, MacIntyre 1994). An other advantage of multiple gene analysis is the possibility of exploring different metabolic pathways and thus getting a more global insight on evolution. This concept has been extensively albeit indirectly - explored by multi-locus enzyme Electrophoresis (MLEE, Bañuls et al. 1999).

However, according to Danchin (1998), genomes are not merely collections of genes, and the map of the cell would be in the chromosome (Danchin \& Hénaut 1997). In other words, rearrangement of genes can either induce or reflect evolutionary changes. This hypothesis proposed for prokaryotes (Danchin \& Hénaut 1997) is documented in higher eukaryotes too and, according to Wilson et al. (1974), gene rearrangements would be more important than point mutations as sources for evolutionary changes. However, very few evolutionary studies have considered gene arrangement as molecular character in trypanosomatids and other 
protozoa, despite their primordial phylogenetic position between prokaryotes and eukaryotes.

\section{MECHANISMS OF GENE REARRANGEMENT AND APPROACHES FOR THEIR ANALYSIS}

A first, direct approach to gene rearrangements can be considered, in which the organisation of specific genes is compared in different taxa. This concept has been applied to the study of a large genomic region containing glucose transporter genes in Trypanosoma brucei, T. congolense, T. vivax, T. cruzi and Leishmania donovani (Bringaud et al. 1998). Gene organisation was shown to be identical in the three Salivarian trypanosomes, but in T. cruzi and Leishmania, insertion of additional genes was observed. Phylogenetic reconstruction based on glucose transporters was in agreement with the monophyly of genus Trypanosoma and the early separation of $T$. vivax from the other Salivarian trypanosomes. Another example concerns the $\alpha$ - and $\beta$-tubulin genes which are linked and organised in alternated tandem repeats in $T$. cruzi (Maingon et al. 1988, Cano et al. 1995) and T. brucei (Tomashow et al. 1983), while they are unlinked in Leishmania and Sauroleishmania (Dujardin 1995, Wincker et al. 1996, Britto et al. 1998). Furthermore, within Leishmania, three types of $\beta$ tubulin gene organisation have been encountered, with gene copies on (i) 3 chromosomes (8/29, 21 and 32 in New World subgenus Leishmania, or NWL and, 8, 21 and 32 in Old World subgenus Leishmania, or OWL; Wincker et al. 1996, Britto et al. 1998), and (ii) 4 chromosomes (1, 8, 21, and 32 in subgenus Viannia, or NWV; Dujardin 1995, Britto et al. 1998). As globins in mammals (Dover et al. 1982, Jeffreys 1982), it is likely that tubulin genes arose from a single copy gene that duplicated, diverged towards $\alpha$ - and $\beta$-tubulin genes, and then began to spread differentially among the genome of the different trypanosomatids. The tracking of this spread among key trypanosomatid taxa would pave the way to new evolutionary hypotheses. However, as for DNA sequence analysis, "one gene rearrangement" trees might also be questioned, and rearrangement of different genes should be studied. This should be feasible in a near future through completion of the different projects of parasite genome sequencing.

A second, indirect approach to gene rearrangement is provided by molecular karyotyping and analysis of chromosome-size variability. This approach infers that chromosome size-polymorphism is reflecting gene rearrangements and it allows to explore the whole nuclear genome. Within genus Leishmania and within T. cruzi, there is conservation of most linkage groups (Henriksson et al. 1995, Wincker et al. 1996, Britto et al. 1998), and chromo- some-specific probes are available for identifying homologous chromosomes. This allowed to visualise chromosome-size differences, the extent of which varies according to the underlying mechanisms, their frequency and possibly their functional consequences. As such, three distinct molecular mechanisms have been described so far as being responsible for chromosome size-variation in trypanosomatids: (1) expansion/contraction of telomeric repeats are responsible for small sizevariations (up to $35 \mathrm{~kb}$ ) and they are reported to happen at a very high frequency, reaching an amplitude of $10 \mathrm{bp} /$ division in T. brucei (Bernards et al. 1983). Functional significance of these phenomena is unknown, but in African trypanosomes, telomere exchange, does play a role in VSG gene switching (Rudenko et al. 1996); (2) amplificationdeletions among tandemly repeated genes cause larger size-differences (up to $400 \mathrm{~kb}$ ) as illustrated in Leishmania (Victoir et al. 1995, Inga et al. 1998, Kebede et al. 1999) and T. cruzi (Wagner \& So 1990, Campetella et al. 1992, Aslund et al. 1994, Henriksson et al. 1995). As for telomeric sequences, size-variation is progressive, but its frequency is lower. In Leishmania, we found rearrangement among the gp63 gene locus (leading to chromosome size-polymorphism) in a strain cultivated over four years (Victoir et al. 1995), while in Sacharomyces cerevisiae the frequency of amplification of rDNA was evaluated at about $5 \times 10^{-3}$ copies/generation (Szostak \& Wu 1980). Considering the importance of the rearranged genes, functional consequences might be expected through (i) gene dosage (Ashburner 1989), (ii) deletion of unique interspersed genes (Bourke et al. 1996), and (iii) effect on intergenic regulatory sequences (Ramamoorthy et al. 1995); (3) fusion/fission events are responsible for the most significant size-differences. For instance in Leishmania, there is a difference of about $1,200 \mathrm{~kb}$ between the $8 / 29$ fused chromosome of NWL and the individual chromosome 8 of OWL and NWV (as calculated from data of Britto et al. 1998). In contrast to previous mechanisms, fusion/ fission is not characterised by stepwise size-variation. Functional consequences are unknown, but considering their low frequency (three in the whole genus Leishmania; Britto et al. 1998), they most probably reflect major evolutionary events.

\section{A NEW METHOD FOR THE ANALYSIS OF CHROMOSOME-SIZE VARIATION: aCSDI}

Interpretation of the extensive chromosome sizepolymorphism among natural populations of parasites remains a main problem. Classically, processing of molecular data and building of trees are based on disjunctive encoding of all the character states (here the size of the different homologues), followed 
by phenetic or cladistic analyses (Gower 1984). By doing so, any chromosome size-difference has the same weight in the analysis. However, as a consequence of the different mechanisms described above, the evolutionary importance of genomic rearrangements seems to vary proportionally to the extent of chromosome-size differences. The only theoretical exception is size-conservative rearrangements such as inversions, which - to our knowledge - are not described so far in trypanosomatids. We may thus assume that phenetic analysis of chromosome size-polymorphism should be based best on the weighing of size-difference, rather than on the disjunctive encoding. Therefore, we developed the measure of the absolute chromosome size difference index (aCSDI; Dujardin et al. 1995), in which the genomic distance between two organisms is simply the sum of the absolute size-differences between their homologous chromosomes. The formulation fits with the diploid state assumed for most chromosomes of trypanosomatids (Henriksson et al. 1990, Bogliolo et al. 1996, Britto et al. 1998), and is very close to the 'absolute genetic distance' of Gregorius (1984), which is considered as having one of the best mathematical properties (Katz 1988). After calculation of aCSDI, agglomeration may be performed by any algorithm like UPGMA (Sneath \& Sokal 1973) or Fitch-Margoliash (Felsenstein 1984). This leads to significantly structured dendrograms in contrast to the ones built-up from disjunctively encoded data (Dujardin et al. 1998). We present hereafter the application of the aCSDI method to three evolutionary models.

\section{INFRA-SPECIFIC EVOLUTION}

The first application of aCSDI concerns analysis at low level of evolutionary divergence, in particular at inter- and intra-specific levels. $L$. (V.) braziliensis, one of the most aggressive species of Latin America, is endemic in the whole Amazonian basin (Guerra 1988). L. (V.) peruviana is a rather benign species, endemic only on the Pacific slopes of the Peruvian Andes and in some inter-Andean valleys, mostly in xerophytic environments (Guerra 1988). Despite these extensive phenotypic differences, the two parasites were shown to differ by only one out of 16 enzymatic loci (Bañuls et al. 2000), an indication of recent divergence (less than 1.5 Myrs, the estimated divergence time between $L$. (L.) infantum and $L$. (L.) donovani, two species differing by two enzymatic loci; Moreno et al. 1986). This even led some authors to question the validity of the distinction of the two species (Chouicha et al. 1997).

In order to better understand the evolutionary relationships between both parasites, an allopatric sampling was performed in their territory of ende- mism. Our sampling key was the bio-geographical units (BGUs) described in Peru on the basis of the endemism of butterfly species (Lamas 1982). Our working hypothesis was that eco-geographical factors responsible for structuring of butterfly species were also responsible for structuring among sand fly vectors and their parasites. Our assumption was supported by the known relationships existing between sand fly and environment (Cameron \& Davies 1993). Five chromosomes (out of 35 in subgenus Viannia, Britto et al. 1998) were selected for their significant size-polymorphism and, analysed using the aCSDI method (Dujardin et al. 1995). All L. (V.) braziliensis isolates grouped together in a small cluster, at distance from $L$. (V.) peruviana (Fig. 1). The latter displayed a much higher chromosome size-polymorphism and its populations were structured according to their BGU of origin along a north-south cline. Northern $L$. (V.) peruviana isolates presented a higher karyotype similarity with $L$. (V.) braziliensis than with southern $L$. (V.) peruviana. Interestingly, the BGU where the northern $L$. (V.) peruviana isolates were collected is close to the pass of Porculla, the only natural pass in the Peruvian Andes between the Amazonian forest and the Pacific slopes. Considering a divergence time of $L$. (V.) peruviana and $L$. (V.) braziliensis inferior to $1.5 \mathrm{Myrs}$ (see above), both species likely diverged after uplifting of the Andes (achieved 3 Myrs ago, Van der Hammen 1982). Accordingly, we think that this dynamic picture of karyotype variation reflects the evolution of $L$. (V.) peruviana from $L$. (V.) braziliensis, in the course of its colonisation of the Pacific slopes of the Andes, through the Porculla pass. Through North-South migration and isolation, $L$. (V.) peruviana would have increased its genetic and genomic differentiation during its journey through the various Pacific BGUs and their respective sand fly species (Davies et al. 1993, Villaseca et al. 1993, Caceres et al. submitted). This trend is corroborated by an important eco-epidemiological argument: evolution from sylvatic (reservoir: rodents and edentates for L.(V.) braziliensis; Guerra 1988) to domestic transmission (reservoir: $\operatorname{dog}$ for $L$. (V.) peruviana; Llanos-Cuentas et al. 1999). Furthermore, this trend was supported recently by genomic evidences: a set of $L$. (V.) braziliensis-specific genes (gp63, Victoir et al. 1998) was found to lack in $L$. (V.) peruviana. Considering the phylogenetic proximity of both species (Chouicha et al. 1997), deletion in $L .(V$.$) peruviana is easier to explain$ than acquisition by sequence divergence in $L$. (V.) braziliensis.

Further studies established that the above-described chromosome size-polymorphism was indeed associated with significant rearrangements (at 


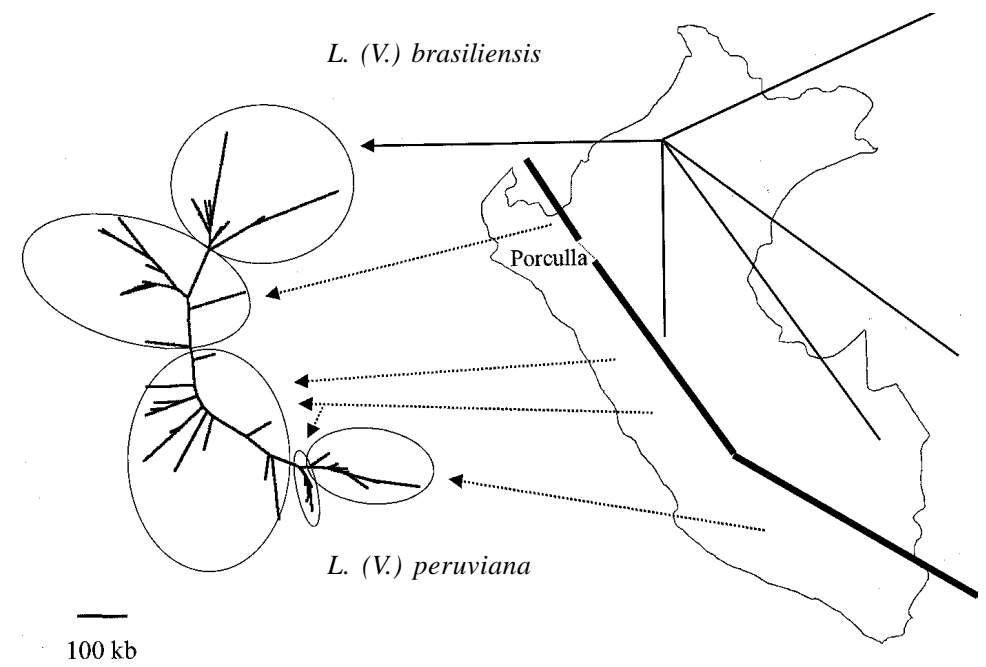

Fig. 1: size-polymorphism of chromosomes 2, 10, 11, 27 and 134Sg in Peruvian Leishmania (V.) braziliensis and L. (V.) peruviana isolates. Agglomeration by the Fitch-Margoliash method after aCSDI calculation. Porculla: natural pass between forest and Pacific slopes of the Andes (thick line)

least in four out five chromosomes studied) among important tandemly repeated genes. First, halving of gp63 gene copy number and deletion of a specific isogene were found to discriminate $L$. (V.) peruviana from $L$. (V.) braziliensis (Victoir et al. 1995). Secondly, decrease in copy number of rDNA (Inga et al. 1998), mini-exon (Kebede et al. 1999) and cystein proteinase b (Polet 1999) was shown to be involved in the North-South chromosome-size decrease observed within $L$. (V.) peruviana.

Our results thus clearly advocate at inter- and infra-specific levels that chromosome size-polymorphism (i) is reflecting gene rearrangements with a potential adaptive significance, (ii) allows a sensitive monitoring of genetic variation (if weighed by aCSDI), and (iii) may be used for inferring novel evolutionary hypotheses.

\section{EVOLUTION WITHIN THE GENUS LEISHMANIA}

In the L. (V.) braziliensis-L. (V.) peruviana model, species divergence is thought to be recent and consequences of gene rearrangements are still visible. Next question was to evaluate if this might still be valid at higher evolutionary level, or if the signal would become buried in the evolutionary noise. Therefore, we processed the data from the karyotypes of major Leishmania species published by Wincker et al. (1996) and Britto et al. (1998), and we calculated the size of each chromosome. It had been shown that, out of 36 chromosomes, 31 linkage groups were preserved across the genus, while five were the object of fusion/fission events (Britto et al. 1998).
We calculated aCSDI between each species, for the 31 "conserved" chromosomes. The ensuing dendrogram (Fig. 2) clearly showed a structuring into three clusters, corresponding to the three major taxonomical categories described by MLEE analysis within genus Leishmania: OWL, NWL and NWV. Interestingly, the genomic distance separating NWL from the two other clusters was quite high (about 1,400 kb). After analysis of individual chromosomes, it appeared that this distance corresponds essentially to a significantly lower size for 11 NWL chromosomes. Such a result should be confirmed by the analysis of additional stocks but, like in the $L$. (V.) braziliensis- $L$. (V.) peruviana model described above, it obviously raises the question about the nature of the sequences implicated in these size-differences. Considering the higher divergence time between NWL and OWL/NWV than between $L$. (V.) braziliensis and $L$. (V.) peruviana, a larger number of significant gene rearrangements might be expected. Accordingly, a specific attention should be paid on the gene content of these 11 chromosomes, as it might give further clues to the functional differences existing between the three major groups of Leishmania. This illustrates the feedback contribution of chromosome evolutionary studies for comparative genomics.

Thus, there is a good qualitative agreement between major evolutionary groups as defined by chromosome size-polymorphism and sequence polymorphism (as inferred by MLEE analysis). Quantitatively, however, relative distances between the three groups are not similar. Indeed, chromosome size analysis positioned NWL as the most 


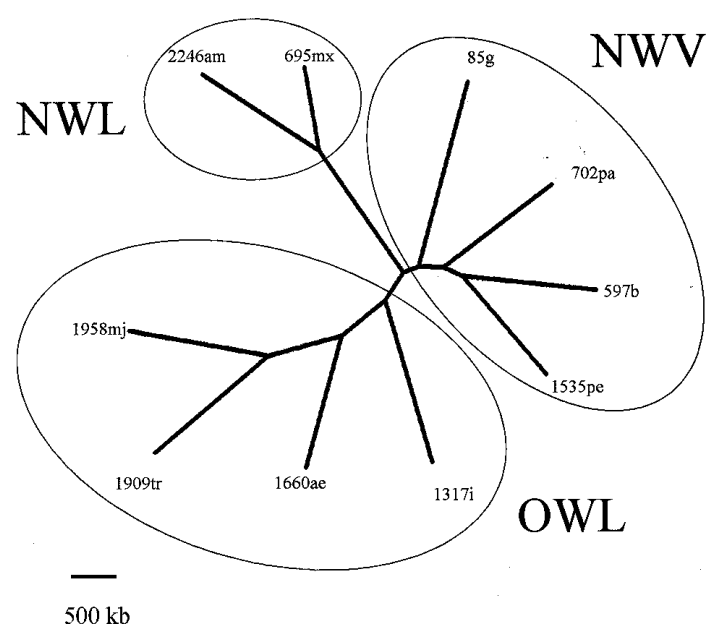

Fig. 2: size-polymorphism of 31 conserved chromosomes in genus Leishmania (from data of Britto et al. 1998 and Wincker et al. 1996) Agglomeration by the FitchMargoliash method after aCSDI calculation. NWV, subgenus Viannia (g, L. (V.) guyanensis ; pa, L. (V.) panamensis; b, L. (V.) braziliensis; pe, L. (V.) peruviana); NWL, New World subgenus Leishmania ( $\mathrm{am}, L$. (L.) amzonensis ; $\mathrm{mx}$, L. (L.) mexicana); OWL, Old World Leishmania (mj, L. (L.) major; tr, L. (L.)tropica; ae, L. (L.) aethiopica; i, $L$. (L.) infantum); numbers correspond to LEM codes of Montpellier.

remote group within genus Leishmania, while MLEE analysis situated NWL and OWL close to each other (Thomaz-Soccol et al. 1993). This remote position of NWL was reinforced by counting the minimal number of fusion/fission events among the five chromosomes not considered by aCSDI analysis. While one event only was separating NWV and OWL, two and three events did separate NWL from OWL and NWV respectively (Britto et al. 1998). Two factors, inconstant mutation rates and/or selection might explain this relative incongruence. The Fitch-Margoliash dendrograms here presented do not consider a molecular clock hypothesis, but even when considering it (Kitch option in Phylip package), the remote position of NWL remained. Unfortunately, the test for molecular clock hypothesis as described by Felsenstein (1984) could not be performed because distances are not independent (on a same gel, chromosome sizes are evaluated from the same molecular marker). Selection was previously shown to play an important role in the modulation of chromosome size-variation in the $L$. (V.) braziliensis-L. (V.) peruviana model (Dujardin et al. 1998), and this hypothesis should be further explored at genus level by analysis of chromosome size-variants genetic content.

Our results thus show that, despite an extensive karyotype plasticity, chromosome size analysis does allow long range evolutionary studies at genus level. Potential outgroups such as Sauroleishmania, Endotrypanum or Crithidia should now be added, in order to better understand the evolutionary relationships within genus Leishmania; among others, this might allow to further document the Paleotropical (Kerr 2000) or Neotropical (Noyes 1998) origin of this genus. Further work is also required to understand the significance of the large genomic differences existing between major groups and to test their eventual adaptive value.

\section{EVOLUTION WITHIN T. CRUZI}

In the next step, our approach was applied to another organism, T. cruzi. This species has been extensively studied by MLEE, RAPD, and natural populations were found to be heterogeneous and highly structured (Brisse et al. 2000). Two major lineages were described, both being very heterogeneous. First lineage (clade 1) was relatively less heterogeneous, and the second one was further subdivided into five smaller lineages (designated clades $2 \mathrm{a}$ to $2 \mathrm{e}$ ). Our aim was thus to evaluate whether chromosome size-polymorphism would also reflect this structuring. Therefore, seven chromosomes recognised by specific probes were analysed in representative stocks of the six T. cruzi major clades, and data were processed by aCSDI (Henriksson et al. in preparation). On the FitchMargoliash dendrogram (Fig. 3), all isolates (without exception) clustered according to their clade of origin. Furthermore, like with MLEE/RAPD, clade 1 was more homogeneous and, consistently with RAPD, quite distant from the other ones. Chromosome discrimination of the six clades lineages might have important biological or medical significance.

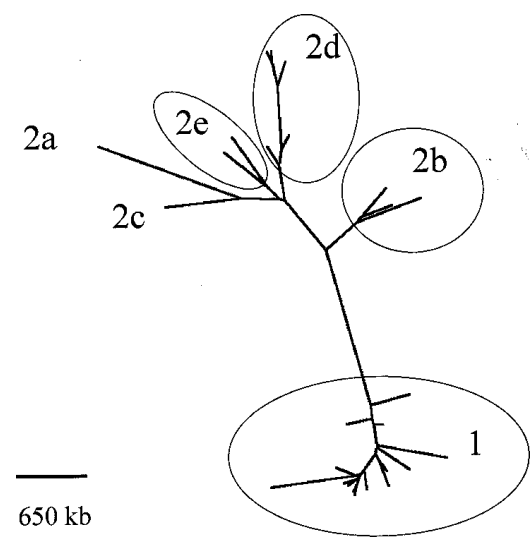

Fig. 3: size-polymorphism of seven chromosomes (recognised by probes $1 \mathrm{~F} 8$, cruzipain, FFAg6, Tc2, CA7.12, CA7.32 and P19; Henriksson et al. 1995) in Trypanosoma cruzi. Agglomeration by the Fitch-Margoliash method after aCSDI calculation. Numbering of clades after Brisse et al. (2000) 
Indeed, significant differences in clinically relevant biological parameters have been reported between isolates belonging to some of these clades (Montamat et al. 1996, Laurent et al. 1997, Revollo et al. 1998, De Lana et al. 1998). Identification of the genes involved in respective chromosome rearrangements will help exploring the molecular bases of these phenotypic differences.

Analysis of individual chromosomes showed a particular size-distribution. Indeed, in most chromosomes, a bi-modal distribution was observed, with important size-differences between the respective modes (Fig. 4). The stepwise size-variation observed within each mode is suggestive of amplification/deletion among tandemly repeated genes, as shown for Leishmania. In contrast, the transition from one mode to the other was not stepwise, and should correspond to discrete but less frequent evolutionary events, like translocation or deletion of large chromosome arms. The occurrence of such mechanisms was supported by the linkage of two markers (CA7.12 and 7.32) on a same chromosome in clade 1, but not in the other clades (Henriksson et al. 1995).

Chromosome analysis of T. cruzi allowed to highlight the relativity of taxonomical subdivisions in trypanosomatids. Indeed, in T. cruzi, the maximal aCSDI value measured (for seven chromosomes) between the two major lineages was $3,500 \mathrm{~kb}$ (average of $500 \mathrm{~kb} / \mathrm{chromosome}$ ). In the whole genus Leishmania, the maximal aCSDI value (for 31 chromosomes) was of $4,750 \mathrm{~kb}$ (average of $150 \mathrm{~kb} / \mathrm{chro}-$ mosome). This result can be accounted for by either a higher mutation rate or a higher frequency of large rearrangements in the species $T$. cruzi, than in genus Leishmania. However, when other genetic characters were considered, like RAPD and MLEE, the same picture was encountered (Bañuls et al. 1999). It appears thus more likely that species definition should be questioned in both cases. In the absence of strict applicability of the sexual exchange criterion (Mayr 1969) to trypanosomatids because of their essentially clonal structure (Tibayrenc et al. 1990), species definition is basically operational only. Our results clearly show that chromosome analysis contributes significantly to the definition of the major evolutionary groups among trypanosomatids, and thus could contribute with other genetic characters for re-definition of corresponding taxonomic units.

\section{CONCLUSIONS AND PROSPECTS}

Trypanosomatids are characterised by extensive genomic plasticity. With the appropriate algorithm (aCSDI), it is possible to rely on chromosome size-polymorphism to infer hypotheses at different evolutionary levels. Qualitative congruence with hypotheses built-up from DNA sequence polymorphism (as inferred here from MLEE and RAPD data) contributed to validate our approach. At low evolutionary level chromosome size-polymorphism involves rearrangement of key genes, with important adaptive value. The same is occurring likely at higher evolutionary levels, where dramatic chromosome size-variations are observed. This should stimulate interaction between evolutionary studies like here presented and parasite genome sequencing projects. On one hand, identification of major evolutionary groups should call for peculiar attention to the genic content of chromosomes responsible for major structuring, and to their potential relationship with biological (including medical) differences. This might be one of the major application of evolutionary studies. On the other hand, definition of linkage groups should be used for performing direct gene rearrangement studies. This is important for further validating indirect studies based on chromosome size-polymorphism, but also for inferring hypotheses at higher evolutionary levels, where chromosome size might not be applicable anymore. It is too early to propose - like in prokaryotes - that the map of trypanosomatid cells is in their chromosomal organisation. However, our results clearly demonstrate that chromosomes together with gene sequences offer useful maps for finding our way in trypanosomatids' evolution.

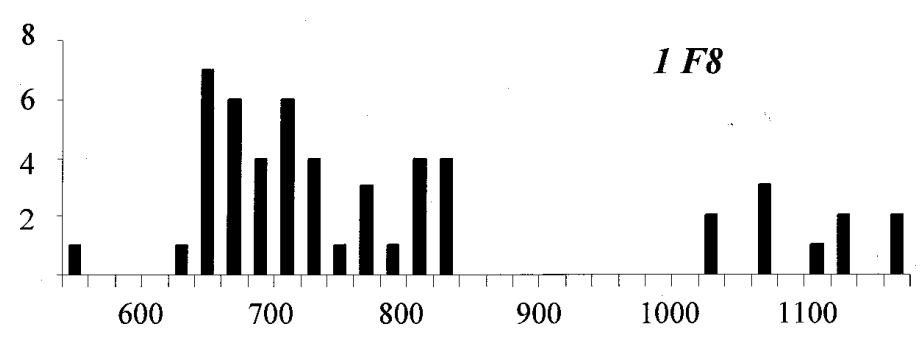

Fig. 4: bi-modal size distribution of 1F8 chromosome in a sample of Trypanosoma cruzi stocks representing the six major clades. Size is expressed in $\mathrm{kb}$. 


\section{ACKNOWLEDGEMENTS}

To Dr Jamie Stevens who organised The Trypanosome Evolution Workshop and stimulated the writing of present review.

\section{REFERENCES}

Ashburner M 1989. Drosophila. A Laboratory Handbook, Cold Spring Harbor Laboratory Press, New York.

Åslund L, Carlsson L, Henriksson J, Rydåker M, Toro GC, Galanti N, Pettersson U 1994. A gene family encoding heterogeneous histone $\mathrm{H} 1$ proteins in Trypanosoma cruzi. Mol Biochem Parasitol 65: 317-330.

Bañuls AL, Hide M, Tibayrenc M 1999. Molecular epidemiology and evolutionary genetics of Leishmania parasites. Int J Parasitol 29:1137-1147.

Bañuls AL, Dujardin JC, Guerrini F, De Doncker S, Jacquet D, Arevalo J, Noël S, Le Ray D, Tibayrenc M 2000. Is Leishmania (Viannia) Peruviana a distinct species? J Eukaryot Microbiol in press.

Bogliolo AR, Lauria-Pires L, Gibson WC 1996. Polymorphisms in Trypanosoma cruzi: evidence of genetic recombination. Acta Trop 61:31-40.

Bourke PF, Holt DC, Sutherland CJ, Kemp DJ 1996. Disruption of a novel open reading frame of Plasmodium falciparum chromosome 9 by subtelomeric and internal deletions can lead to loss or maintenance of cytoadherence. Mol Biochem Parasitol 82: 25-36.

Bringaud F, Vedrenne C, Cuvillier A, Parzy D, Baltz D, Tetaud E, Pays E, Venegas J, Merlin G, Baltz T 1998. Conserved organisation of genes in trypanosomatids. Mol Biochem Parasitol 94: 249-264.

Brisse S, Barnabé C, Tibayrenc M 2000. Identification of six Trypanosoma cruzi phylogenetic lineages by random amplified polymorphic DNA and multilocus electrophoresis. Int J Parasitol 30: 35-44.

Britto C, Ravel C, Bastien P, Blaineau C, Pagès M, Dedet JP, Wincker P 1998. Conserved linkage groups associated with large-scale chromosomal rearrangements between Old World and New World Leishmania genomes. Gene 222: 107-117.

Caceres AG, Villaseca P, Dujardin JC, Bañuls AL, Inga R, Lopez M, Arana M, Le Ray D, Arevalo J. Geographic insulation of Andean cutaneous leishmaniasis: Lutzomyia ayacuchensis (Diptera: Psychodidae) vector of Uta. Paper submitted to Am J Trop Med Hyg.

Cameron MM, Davies CR 1993. Ecological studies support a key role for aphid honeydew as a nutrient source for sandflies. Trans R Soc Trop Med Hyg 87: 363.

Campetella O, Henriksson J, Åslund L, Frasch ACC, Pettersson U, Cazzulo JJ 1992. The major cysteine proteinase (cruzipain) from Trypanosoma cruzi is encoded by multiple polymorphic tandemly organized genes located on different chromosomes. $\mathrm{Mol}$ Biochem Parasitol 50: 225-234.

Cano MI, Gruber A, Vazquez M, Cortes A, Levin MJ, Gonzalez A, Degrave W, Rondinelli E, Zingales B, Ramirez JL, Alonso C, Requena JM, Da Silveira JF 1995. Molecular karyotype of clone CL Brener chosen for the Trypanosoma cruzi genome project. Mol Biochem Parasitol 71: 273-278.
Chouicha N, Lanotte G, Pratlong F, Cuba Cuba CA, Velez ID, Dedet JP 1997. Phylogenetic taxonomy of Leishmania (Viannia) braziliensis based on isoenzymatic study of 137 isolates. Parasitology 115: 343-348.

Danchin A 1998. The Delphic boat or what the genomic text tell us. Bioinformatics 14: 383.

Danchin A, Hénaut A 1997. The map of the cell is in the chromosome. Curr Opin Genet Dev 7: 852-854.

Davies CR, Fernandez M, Paz L, Roncal N, LlanosCuentas A 1993. Lutzomyia verrucarum can transmit Leishmania peruviana, the aetiological agent of Andean cutaneous leishmaniasis. Trans $R$ Soc Trop Med Hyg 87: 603-606.

De Lana M, da Silveira Pinto A, Barnabe C, Quesney V, Noel S, Tibayrenc M 1998.Trypanosoma cruzi: compared vectorial transmissibility of three major clonal genotypes by Triatoma infestans. Exp Parasitol 90: 20-25.

Dover G, Brown S, Coen E, Dallas J, Strachan T, Trick M 1982. The dynamics of genome evolution and species differentiation. In Dover \& Flavell (eds), Genome Evolution, Academic Press, London, p. 343-374.

Dujardin JC 1995. Significations de la Variabilité Caryotypique dans les Populations Naturelles de Leishmanies Néotropicales, $\mathrm{PhD}$ Thesis, Vrije Universiteit, Brussel.

Dujardin JC, Dujardin JP, Tibayrenc M, Timperman G, De Doncker S, Jacquet D, Arevalo J, Llanos-Cuentas A, Guerra H, Bermudez H, Hamers R, Le Ray D 1995. Karyotype plasticity in Neotropical Leishmania: an index for measuring genomic distance among $L$. (V.) peruviana and L. (V.) braziliensis populations. Parasitology 110: 21-30.

Dujardin JC, Bañuls AL, Arevalo J, Tibayrenc M, Le Ray D 1998. Comparison of chromosomal and isoenzymatic variation in eco-geographical populations of Leishmania (Viannia) peruviana. Parasitology 117: 547-554.

Felsenstein J 1984. Distance methods for inferring phylogenies: a justification. Evolution 38: 16-24.

Gower JC 1984. Numerical methods of classification. In JA Rioux, Leishmania. Taxonomie et Phylogenèse. Applications Éco-épidémiologiques, IMEEE, Montpellier, p. 13-20.

Guerra H 1988. Distribution of Leishmania in Peru. In Walton,Wijeyaratne \& Modabber (eds), Research on Control Strategies for the Leishmaniases, IDRC-MR 184e, Ottawa, p. 135-145.

Gregorius HR 1984. A unique genetic distance. Biometrics $J$ 26: 13-18.

Henriksson J, Åslund L, Macina RA, Franke de Cazzulo BM, Cazzulo JJ, Frasch AC, Pettersson U 1990. Chromosomal localization of seven cloned antigen genes provides evidence of diploidy and further demonstration of karyotype variability in Trypanosoma cruzi. Mol Biochem Parasitol 42: 213-223.

Henriksson J, Porcel BM, Rydåker M, Sabaj V, Galanti N, Ruiz AM, Cazzulo JJ, Frasch ACC, Pettersson U 1995. Chromosome-specific markers reveal conserved linkage groups in spite of extensive chromosomal size variation in Trypanosoma cruzi. Mol Biochem Parasitol 73: 63-74. 
Inga R, De Doncker S, Gomez J, Lopez M, Garcia R, Le Ray D, Arevalo J, Dujardin JC 1998. Relation between variation in copy number of ribosomal RNA encoding genes and size of harbouring chromosomes in Leishmania of subgenus Viannia. Mol Biochem Parasitol 92: 219-228.

Jeffreys AJ 1982. Evolution of globin genes. In Dover \& Flavell (eds), Genome Evolution, Academic Press, London UK, p.157-176.

Katz M 1988. A comparative statistical analysis of genetic distances. I - Estimation of distances and their variances; distribution of the estimators. Biometrics J 30: 571-587.

Kebede A, De Doncker S, Arevalo J, Le Ray D, Dujardin JC 1999. Leishmania of subgenus Viannia: size polymorphism of chromosomes bearing mini-exon genes in natural populations is due to rearrangement of the mini-exon gene array. Int J Parasitol 29: 549-557.

Kerr SF 2000. Palaearctic origin of Leishmania. Mem Inst Oswaldo Cruz 95: 75-80.

Lamas G 1982. A preliminary zoogeographical division of Peru, based on butterfly distributions (Lepidoptera, Papilionoidea). In Prance (ed.), Biological Diversification in the Tropics, Columbia University Press, New York, p. 336-357.

Larson A 1994. The comparison of morphological and molecular data in phylogenetic systematics. In Schierwater, Streit, Wagner \& DeSalle (eds), Molecular Ecology and Evolution: Approaches and Applications, Birkhäuser Verlag, Basel, p. 371-390.

Laurent JP, Barnabe C, Quesney V, Noel S, Tibayrenc M 1997. Impact of clonal evolution on the biological diversity of Trypanosoma cruzi. Parasitology 114: 213-218.

Llanos-Cuentas EA, Roncal N, Villaseca P, Paz L, Ogusuku E, Perez JE, Caceres A, Davies CR 1999. Natural infections of Leishmania peruviana in animals in the Peruvian Andes. Trans $R$ Soc Trop Med Hyg 93: 15-20.

MacIntyre RJ 1994. Molecular evolution: codes, clocks, genes and genomes. BioEssays 16: 699-703.

Maingon R, Gerke R, Rodriguez M, Urbina J, Hoenicka J, Negri S, Aguirre T, Nehlin J, Knapp T, Crampton J 1988. The tubulin genes of Trypanosoma cruzi. Eur J Biochem 171: 285-291.

Mayr E 1969. Principles of Systematic Zoology, McGrawHill, New York, 428 pp.

Montamat EE, De Luca D’Oro GM, Gallerano RH, Sosa R, Blanco A. 1996. Characterization of Trypanosoma cruzi populations by zymodemes: correlation with clinical picture. Am J Trop Med Hyg 55: 625-628.

Moreno G, Rioux JA, Lanotte G, Pratlong F, Serres E 1986. Le complexe Leishmania donovani s.l. Analyse enzymatique et traitement numérique. Individualisation du complexe L. infantum. Corollaires biogéographiques et phylétiques à propos de 146 souches originaires de l'Ancien et du Nouveau Monde. In JA Rioux, Leishmania. Taxonomie et Phylogenèse. Applications Éco-épidémiologiques, IMEEE, Montpellier, p. 105-117.

Noyes H 1998. Implications of a Neotropical origin of the Genus Leishmania. Mem Inst Oswaldo Cruz 93: 657-662.
Polet S 1999. Etude du Dosage des Gènes Cystéine Protéinase dans les Populations Naturelles de Leishmanies Péruviennes, L.Sc.Thesis, Namur, Belgium, $59 \mathrm{pp}$.

Ramamoorthy R, Swihart KG, McCoy JJ, Wilson ME, Donelson JE 1995. Intergenic regions between tandem gp63 genes influence differential expression of gp63 RNAs in Leishmania chagasi promastigotes. $J$ Biol Chem 270: 12133-12139.

Revollo S, Oury B, Laurent JP, Barnabe C, Quesney V, Carriere V, Noel S, Tibayrenc M 1998. Trypanosoma cruzi: impact of clonal evolution of the parasite on its biological and medical properties. Exp Parasitol 89: 30-39.

Rudenko G, McCulloch R, Dirks-Mulder A, Borst P 1996. Telomere exchange can be an important mechanism of variant surface glycoprotein gene switching in Trypanosoma brucei. Mol Biochem Parasitol 80: 65-75.

Sneath PHA, Sokal RR 1973. Numerical Taxonomy, Freeman, San Fransico, 573 pp.

Szostak JW, Wu R 1980. Unequal crossing over in the ribosomal DNA of Saccharomyces cerevisiae. $\mathrm{Na}$ ture 284: 426-430.

Thomaz-Soccol V, Lanotte G, Rioux JA, Pratlong F, Martini-Dumas A, Serres E 1993. Monophyletic origin of the genus Leishmania Ross, 1903. Ann Parasitol Hum Comp 68:107-108.

Tibayrenc M, Kjelleberg F, Ayala FJ 1990. A clonal theory of parasitic protozoa: the population structures of Entamoeba, Giardia, Leishmania, Naegleria, Plasmodium, Trichomonas and Trypanosoma and their medical and taxonomical consequences. Proc Natl Acad Sci USA 87: 2414-2418.

Tomashow LS, Milhausen M, Rutter W, Agabian N 1983. Tubulin genes are tandemly linked and clustered in the genome of Trypanosoma brucei. Cell 32: 35-43.

Van der Hammen T 1982. Paleoecology of Tropical South America. In Prance (ed.), Biological Diversification in the Tropics, Columbia University Press, New York, p. 60-66.

Victoir K, Dujardin JC, De Doncker S, Barker DC, Arevalo J, Hamers R, Le Ray D 1995. Plasticity of gp63 gene organisation in Leishmania (Viannia) braziliensis and Leishmania(Viannia) peruviana. Parasitology 111: 265-273.

Villaseca P, Llanos-Cuentas A, Perez E, Davies CR 1993. A comparative study of the relative importance of Lutzomyia peruensis and Lutzomyia verrucarum as vectors of cutaneous leishmaniasis in the Peruvian Andes. Am J Trop Med Hyg 49: 260-269.

Wagner W, So M 1990. Genomic variation of Trypanosoma cruzi: involvement of multicopy genes. Infect Immun 58: 3217-3224.

Wilson AC, Sarich VM, Maxson LR 1974. The importance of gene rearrangement in evolution: evidence from studies on rates of chromosomal, protein and anatomical evolution. Proc Natl Acad Sci USA 71: 3028-3030.

Wincker P, Ravel C, Blaineau C, Pagès M, Jauffret Y, Dedet JP, Bastien P 1996. The Leishmania genome comprises 36 chromosomes conserved across widely divergent human pathogenic species. Nucleic Acids Res 24: 1688-1694. 